\title{
Analysis on the Characteristics of Tourism Flow of Chinese Independent Tourists in Vietnam
}

\author{
Chun-Yan Wang ${ }^{1} \&$ Hyung-Ho Kim ${ }^{2}$ \\ ${ }^{1}$ Department of Business Management, Jilin Engineering Normal University, Changchun, China \\ ${ }^{2}$ Department of Air Transport and Logistics, Sehan University, Chungnam, South Korea \\ Correspondence: Hyung-Ho Kim, Professor, Department of Air Transport and Logistics, Sehan University, 33 \\ Sehandae-gil, Sinpyung-eup, DangJin-Si, Chungnam, 31746, South Korea. Tel: 82-10-2071-8977. E-mail: \\ hhkim@sehan.ac.kr
}

Received: April 9, 2020

Accepted: May 9, 2020

Online Published: May 23, 2020

doi:10.5430/rwe.v11n2p122

URL: https://doi.org/10.5430/rwe.v11n2p122

\begin{abstract}
Background/Objectives: As Vietnam's largest tourists-generating country, China is an important tourism market for Vietnam.

Methods/Statistical analysis: Through data mining and classification of online travel notes for Chinese independent tourists to Vietnam, this study analyzes the characteristics of tourism nodes of Chinese independent tourists in Vietnam by using the social network analysis method.

Findings: The results showed that Ha Noi, Ho Chi Minh, Da Nang, Nha Trang, Da Lat were the main tourist destinations for Chinese independent tourists in Vietnam. Cities such as Ha Noi, Ho Chi Minh, Da Nang, Lao Cai, NhaTrang, Dalat have strong degree centrality that have strong aggregation and radiation ability to other tourism nodes. The closeness centrality of Ha Noi, Ho Chi Minh, Da Nang, Lao Cai, Nha Trang, Da Lat is higher that reflets the mobility and accessibility between these travel nodes and other nodes is good. Ha Noi, Ho Chi Minh, Da Lat, Da Nang and Lao Cai have high betweenness centrality, and they have strong control over other tourism nodes. This study once again verifies the research value of online travel notes, and the results can provide scientific basis for developing the regional tourism, designing the tourism routes, improving the tourism service facility and planning the tourism traffic in Vietnam.
\end{abstract}

Improvements/Applications: The source of tourism flow of Chinese independent tourists to Vietnam should be studied, providing a basis for Vietnam to develop China's tourism market and make precise marketing.

Keywords: social network analysis, online travel notes, tourism flow, Chinese independent tourists, Vietnam tourism

\section{Introduction}

Since the restoration of friendly relations between China and Vietnam in 1991, both countries have focused on economic development, and have gradually begun to conduct economic and cultural cooperation and exchanges, especially in tourism. In recent years, the Vietnamese government has carried out in-depth development of its tourism resources and issued many policies that are beneficial to tourists. The development speed of tourism has been significantly improved, and the number of Chinese tourists received by Vietnam has increased rapidly. According to the statistics results from Vietnam's bureau of statistics, the number of Chinese tourists to Vietnam has been increasing year by year since 2016. In 2018, the number of Chinese tourists to Vietnam reached 4966.5 thousand arrivals. Although the growth rate of Chinese tourists slowed down in 2017 and 2018, the total number of Chinese tourists to Vietnam is still very significant (shown in Figure 1). Vietnam's main tourists-generating countries are China, South Korea, Japan, the United States and Russia. China has long been the largest tourists-generating country for Vietnam.

With the rapid development of China's economy and the continuous improvement of living standards, Chinese outbound tourism has become more common, and more and more Chinese tourists prefer to choose independent travel to abroad. According to the 2017 survey of Chinese tourists' intentions released by Ctrip.com, $58.6 \%$ of Chinese tourists want to travel by DIY tour. In addition, the distance between the China and Vietnam is not far. With the convenient transportation, the cheap price, and similar culture, more and more Chinese independent tourists choose to 
travel to Vietnam by DIY tour. China has become a huge potential tourists-generating country for Vietnam's inbound tourism. The global destination analysis report (2017), jointly released by China Tourism Academy (CTA) and mafengwo.com, shows that short-haul destinations in southeast Asia, such as Vietnam and Thailand, are the most popular destinations for Chinese tourists.

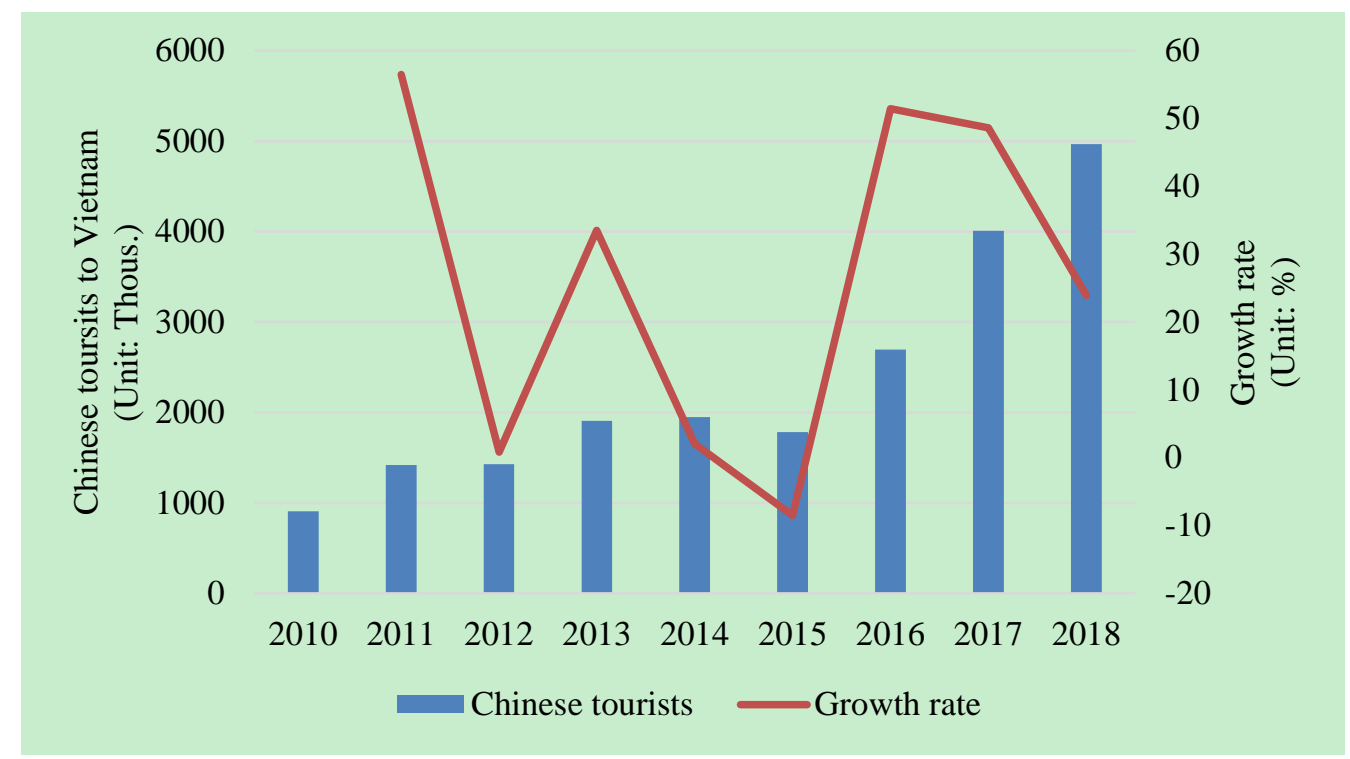

Figure 1. Number of Chinese tourists to Vietnam from 2010 to 2018 (The Statistics of Chinese tourists to Vietnam, 2019)

Faced with the huge number of Chinese tourists, the distribution of tourism infrastructure in Vietnam is unbalanced and imperfect. If we can understand the destination selection tendency of Chinese tourists, and grasp the flow direction of Chinese tourists, Vietnam tourism industry will have appropriate measures to adjust or control the number of tourists, improve the tourist attractions in time, and provide a more comfortable travel environment for tourists. The study on the characteristics of tourist flow of Chinese independent tourists to Vietnam is conducive to the rational establishment and planning of tourist routes in the future, which is of great application value to the development of tourism resources and tourism market.

\section{Theoretical Background}

\subsection{Tourism Flow}

European and American scholars have begun to study the tourism flow theory and concept for a long time. Tourism flow is a combination of tourism logistics, information flow, capital flow, technology flow and cultural flow (Leiper, 1990). It includes three elements: the direction of tourists-generating region and destination, the connection mode and the flow density (Bowden, 2003). Tourism flows can be divided into domestic and international tourism flows (Williams and Zelinsky, 1970; Jansen-Verbeke and Spee, 1995). Some scholars have analyzed the tourism flow and its influencing factors from South Korea to Australia from the perspective of time series (Lim, 2004). In addition, some scholars' researches mainly focus on the definition of tourism flow, dynamic regulation of inbound tourism flow, information system of tourism flow, spatial and temporal evolution characteristics of tourism flow, etc. (Wang et al., 2013; Wu, 2014; Wu et al., 2016).

\subsection{Social Network}

Social network theory focuses on the role of social relations in transmitting information, guiding the influence of individuals or media, and promoting attitude or behavior change (Freeman, 2004). Since the 1960s, with the application of network analysis methods in a variety of empirical backgrounds, social network theory has greatly expanded the scope of media effect research. Three distinct intuitive conceptions of centrality is proposed for measuring the centrality of positions and the degree of centralization (Freeman, 1978). The methods of measuring centrality are different, which can be generally divided into degree centrality, closeness centrality, eigenvector 
centrality and betweenness centrality, etc. (Yan et al., 2013).

\subsection{Core and Periphery Theory}

The core and periphery theory was first proposed by J. Friedman in 1966. In 1969, he proposed the "core and periphery" spatial polarization as an adaptive theoretical model to explain the unbalanced development process between different regions or between urban and rural areas (Borgatti and Everett, 2000). He believes that any spatial economic system can be decomposed into core areas and peripheral areas with different properties. This theory tries to explain how a region changes from the situation of no relationship and isolated development to the situation of unbalanced development related to other regions, and then changes from extremely unbalanced development to a regional system with relationship and balanced development.

\section{Research Method and Data Sources}

\subsection{Research Method}

Social Network Analysis is a recently emerging analytical method and has become a key technology in modern sociology. It has gained wide attention in anthropology, biology, demography, economics, geography, history, information science and other fields. The goal of the social network analysis is to explain the community by mapping the relationship between the community as a network, and then to try to find the key connections among individuals, groups or individuals in the network. Networks are simply points (or nodes) connected by links. Generally, in social network analysis, nodes are people (or things) and links are any social connection between them. This method can also be used to analyze the relationship characteristics between tourism nodes (Wang et al., 2019; Wang et al., 2019).

This study chooses to use the social network theory and method to analyze the characteristics of the tourism flow network of Chinese independent tourists to Vietnam. The centrality analysis of tourist nodes includes degree centrality analysis, closeness centrality analysis and betweenness centrality analysis.

Centrality represents the degree to which a node is at the core of the network; in other words, centrality represents the nature of a single node. This study mainly focuses on degree centrality, closeness centrality and betweenness centrality.

\subsubsection{Degree Centrality}

In a network, a node is at the center when it is in direct contact with many other nodes. That is, the wider the relationship between nodes and the more adjacent nodes, the more important this node will be. The number of connections between two nodes can determine the index of where the nodes are in the tourism network. The higher the degree centrality is, the more central the node is.

\subsubsection{Closeness Centrality}

Closeness centrality reflects the closeness between one node and other nodes in the network. The reciprocal of the shortest path distance from one node to all other nodes indicates closeness centrality. That is, for one tourism nodes, the closer it is to other nodes, the greater its closeness centrality.

\subsubsection{Betweenness Centrality}

Betweenness centrality is an index to describe the importance of a node based on the shortest path data passing through a node. In other words, this node is like a gate, and any node that is connected to it has to go through it to get to any other node. To know what role a node plays in the whole travel network, we can measure it by the index of betweenness centrality. The betweenness centrality of a node is proportional to its control over the tourism flow network and to the dependence of other tourism nodes on it.

\subsection{Data Sources}

The data of this study mainly come from the content of online travel notes on the website of http://mafengwo.cn and http://www.qyer.com. As the leading travel and entertainment platforms and outbound travel service platforms in China, both of them have accumulated a large amount of tourism content in the field of User Generated Content (UGC). In this study, the crawler software was used to get online travel notes of Chinese independent tourists to Vietnam from January 2017 to October 2019 on the website of http://mafengwo.cn and http://www.qyer.com. From a total of 2056 online travel notes, 803 which met the research needs and included the complete itinerary were selected (among which 535 were from http://mafengwo.cn, 268 were from http://www.qyer.com), 207 online travel notes in 2017, 317 online travel notes in 2018, and 279 online travel notes in 2019 According to the actual travel track of tourists, 803 online travel notes meeting the screening criteria were edited in EXCEL, such as HoChiMinh--DaLat--NhaTrang--DaNang, and 3871 travel nodes were collected. 


\section{Results and Discussion}

\subsection{Network Structure of Chinese Independent Tourists to Vietnam}

Convert the travel nodes data collected in Excel, import this Excel file into Gephi 0.9.2 software, and then draw the Network structure chart of Chinese independent tourists to Vietnam from 2017 to 2019 (see Figure 2). Then, the degree centrality, closeness centrality and betweenness centrality indexes of Vietnam's tourism nodes was calculated (see Table 1).

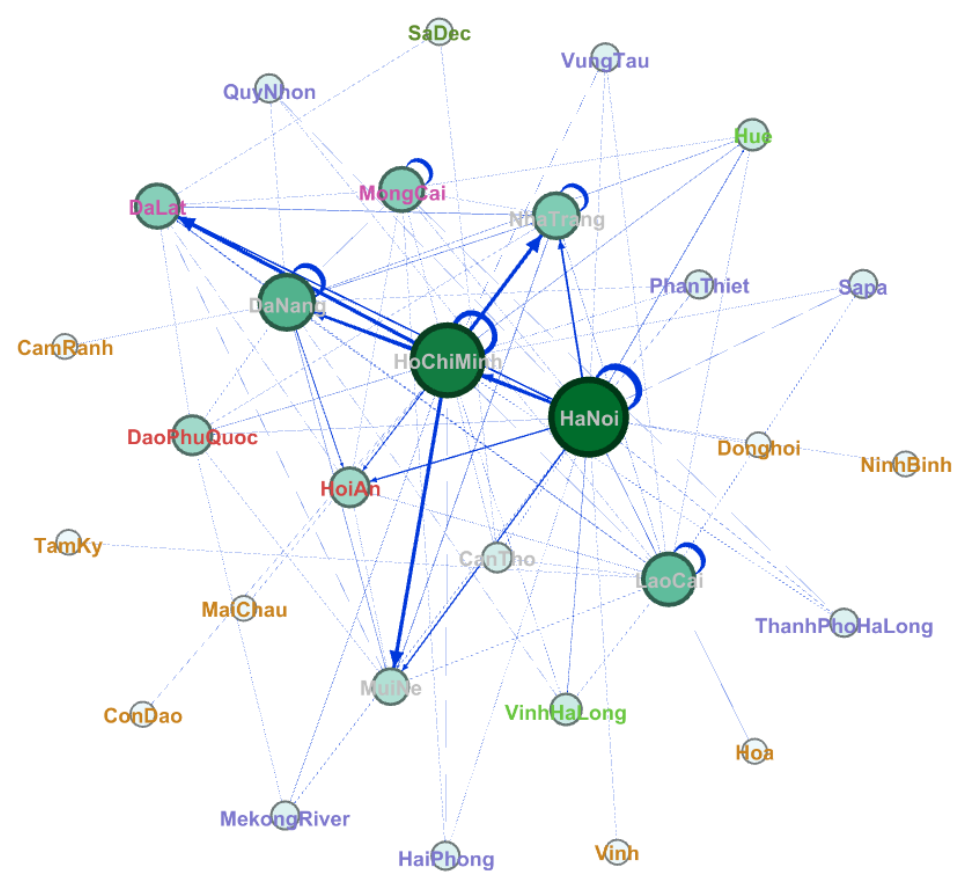

Figure 2. Network structure of Chinese independent tourists to Vietnam from 2017 to 2019

The 29 nodes in Figure 2 represent the main travel nodes of Chinese independent tourists to Vietnam. As can be seen from Figure 2, HoNai and Ho Chi Minh appears most frequently, so they are the two largest tourist destination for Chinese independent tourists to Vietnam. In addition, other important tourist destinations include Da Nang, Nha Trang, Da Lat, Mong Cai, Lao Cai, Dao Phu Quoc, Mui Ne and Hoi An. In terms of geographical distribution, Vietnam can be divided into three major tourist areas: northern tourist area, central tourist area and southern tourist area. The northern tourist area is centered on Ha Noi, radiating to Vinh Ha Long and Lao Cai; the central tourist area is centered on Da Nang, which radiates to Hoi An, Mui Ne and Dao Phu Quoc; and in the south tourist area, it is centered on Ho Chi Minh, radiating to Da Lat, Nha Trang, Da Nang, MuiNe and other surrounding areas. 
Table 1. Indicators of tourism nodes in Vietnam

\begin{tabular}{|c|c|c|c|c|c|}
\hline $\begin{array}{c}\text { Tourism } \\
\text { Nodes }\end{array}$ & $\begin{array}{c}\text { Degree } \\
\text { centrality }\end{array}$ & In-degree & Out-degree & $\begin{array}{l}\text { Closeness } \\
\text { centrality }\end{array}$ & $\begin{array}{c}\text { Betweenness } \\
\text { centrality }\end{array}$ \\
\hline HaNoi & 33 & 9 & 24 & 0.871 & 0.138 \\
\hline HoChiMinh & 30 & 9 & 21 & 0.794 & 0.094 \\
\hline DaNang & 20 & 7 & 13 & 0.628 & 0.025 \\
\hline LaoCai & 18 & 3 & 15 & 0.675 & 0.014 \\
\hline NhaTrang & 14 & 7 & 7 & 0.551 & 0.002 \\
\hline DaLat & 13 & 9 & 4 & 0.519 & 0.038 \\
\hline MongCai & 13 & 3 & 10 & 0.587 & 0 \\
\hline HoiAn & 10 & 6 & 4 & 0.491 & 0 \\
\hline DaoPhuQuoc & 10 & 4 & 6 & 0.540 & 0.002 \\
\hline MuiNe & 8 & 8 & 0 & 0 & 0 \\
\hline Hue & 5 & 5 & 0 & 0 & 0 \\
\hline VinhHaLong & 5 & 4 & 1 & 0.474 & 0 \\
\hline CanTho & 4 & 4 & 0 & 0 & 0 \\
\hline MekongRiver & 3 & 3 & 0 & 0 & 0 \\
\hline PhanThiet & 3 & 3 & 0 & 0 & 0 \\
\hline QuyNhon & 3 & 3 & 0 & 0 & 0 \\
\hline Sapa & 3 & 3 & 0 & 0 & 0 \\
\hline $\begin{array}{l}\text { ThanhPhoHa } \\
\text { Long }\end{array}$ & 3 & 3 & 0 & 0 & 0 \\
\hline VungTau & 3 & 3 & 0 & 0 & 0 \\
\hline HaiPhong & 3 & 3 & 0 & 0 & 0 \\
\hline SaDec & 2 & 0 & 2 & 0.359 & 0 \\
\hline Hoa & 1 & 1 & 0 & 0 & 0 \\
\hline Donghoi & 1 & 1 & 0 & 0 & 0 \\
\hline Vinh & 1 & 1 & 0 & 0 & 0 \\
\hline NinhBinh & 1 & 1 & 0 & 0 & 0 \\
\hline TamKy & 1 & 1 & 0 & 0 & 0 \\
\hline CamRanh & 1 & 1 & 0 & 0 & 0 \\
\hline ConDao & 1 & 1 & 0 & 0 & 0 \\
\hline MaiChau & 1 & 1 & 0 & 0 & 0 \\
\hline Mean Value & 7.379 & 3.690 & 3.690 & 0.224 & 0.011 \\
\hline Max & 33 & 9 & 24 & 0.871 & 0.138 \\
\hline Min & 1 & 1 & 0 & 0 & 0 \\
\hline
\end{tabular}

As Vietnam is a long and narrow country with a length of about 1600 kilometers from north to south, only 50 kilometers from east to west (at the narrowest) and has a long coastline of more than 3,260 kilometers, many Chinese independent tourists choose to travel from north to south or from south to north in Vietnam. According to the analysis of the content of online travel notes, there are two main ways for Chinese tourists to enter Vietnam. One is by land, which is to enter the Vietnam by train or bus through border ports in Guangxi Province or Yunnan Province of China. The other is the air route, which flies directly to major Vietnamese cities with international airports, such as Hanoi, Da Nang, Ho Chi Minh and so on. So Ho Chi Minh, which has Vietnam's largest international airport, Ha Noi, which has the second largest international airport and trains to China, and Nha Trang, which is next to Cam Ranh international airport, have become important tourist destinations for Chinese independent tourists entering Vietnam. Ho Chi Minh is an important hub for traveling, which has the most connections with other tourist cities in Vietnam, as well as Ha Noi and Nha Trang.

\subsection{Network Structure Characteristics of Tourism Nodes}

\subsubsection{Degree Centrality}

From the perspective of degree centrality, there are 29 tourism nodes, and each of them has tourism flow agglomeration and radiation connection with 7.379 other nodes. Ha Noi ranks first in terms of in-degree centrality and 
out-degree centrality, indicating that it has a strong cohesion and radiation effect on tourism flow, and is the distribution node of independent tourism flow in Vietnam. Ha Noi, Ho Chi Minh, Da Nang, Lao Cai, Nha Trang, Da Lat, Mong Cai, Hoi An, Dao Phu Quoc, Mui Ne and other cities all have degree centrality values greater than the mean value of 7.379 (see Table 1), which can be considered to be at the core of the network with strong aggregation and radiation capabilities. The reason why these cities have such an important position is because of the important geographical and political and cultural location of these sites in Vietnam.

First, as the capital of Vietnam, Ha Noi is located in the Red River Delta in the north of Vietnam, which is the political, economic and cultural center of Vietnam as well as the transportation hub in the north of Vietnam. Thanh Pho Ha Long, Vinh Ha Long, Sapa and other tourist destinations around Hanoi have also become ideal destinations for Chinese independent tourists in northern Vietnam. Secondly, Da Nang, Hoi An and Hue are located in central Vietnam and form a triangle. Da Nang have international airports and are important destinations for Chinese independent tourists entering Vietnam. Finally, Ho Chi Minh, Nha Trang, Da Lat and Mui Ne are all located in the south of Vietnam. Among them, Ho Chi Minh City is the largest city in Vietnam and the economic and cultural center in the south of Vietnam. It has a high reputation, perfect infrastructure and convenient transportation. Nha Trang is located in the coastal region of south and central Vietnam, with the most beautiful beaches in Vietnam, and is a famous seaside resort. Da Lat and Mui Ne are close to Nha Trang, and its scenery is totally different from that of Nha Trang.

\subsubsection{Closeness Centrality}

Closeness centrality measures the effectiveness and smoothness of tourists' transfer and diffusion between tourism nodes. The closeness centrality of Ha Noi, Ho Chi Minh, Da Nang, Lao Cai, Nha Trang, Da Lat, Mong Cai, Hoi An, Dao Phu Quoc, Vinh Ha Long and Sa Dec is higher than the average value of 0.224, which reflects that the mobility and accessibility between these nodes and other nodes is good and controlled by other nodes. They are in the center of the whole network, and these tourism nodes are generally included in the different tourism routes of Chinese independent tourists. From Fig. 2, it can be clearly seen that the closeness centrality of Ha Noi, Ho Chi Minh, Da Nang and Lao Cai is higher in the network. They are a little controlled by other tourism nodes, which are the first tourism destination for Chinese independent tourists to Vietnam. These tourism nodes also have rich tourism resources, which can be used as the destination of 2-5 day sightseeing tour in Vietnam.

\subsubsection{Betweenness Centrality}

Betweenness centrality is an important index to measure the bridge and transit function of a node in the whole network. The betweenness centrality of Ha Noi, Ho Chi Minh, Da Lat, Da Nang and Lao Cai is all higher than the mean value of 0.138 (see Table 1), indicating that these five travel nodes have strong control over other travel nodes in the tourism flow network of Chinese independent tourists to Vietnam. These five tourism nodes are all located in an important geographical location and very convenient transportation conditions. Ha Noi, Ho Chi Minh and Da Nang have direct airlines to China. Lao Cai is an important tourist transit point for Chinese independent tourists entering Vietnam from the northern border. It connects Thanh Pho Ha Long, Vinh HaL ong, Hai Phong and other tourism nodes. Da Lat is a famous tourism attraction between Ho Chi Minh and Da Nang. It is the only way or choice for Chinese independent tourists from south to north in Vietnam.

\section{Conclusion}

Based on the data mining of online travel notes, this study constructed the network structure chart of Chinese independent tourists in Vietnam, conducted an in-depth study on the characteristics of its tourism nodes, and obtained the following conclusions: First, Ha Noi, Ho Chi Minh, Da Nang, Nha Trang, Da Lat, Mong Cai, Lao Cai, Dao Phu Quoc, Mui Ne and Hoi An are the most frequent tourist destinations for Chinese tourists to Vietnam. Ha Noi and Ho Chi Minh is the two largest tourist destination for Chinese independent tourists to Vietnam. Some natural beauty, such as Phong Nha-Ke Bang National Park, etc., is located in the inland of Vietnam because of its inadequate infrastructure or inconvenience transportation, does not favor by Chinese independent tourists. In the future, Vietnam tourism industry can consider improving the tourism infrastructure and transportation system in those areas, develop more tourism hotspots to rich the tourist attractions in Vietnam, and use new tourism hotspots to improve the revisit rate of Chinese independent tourists. Secondly, from the perspective of network node characteristics, cities such as Ha Noi, Ho Chi Minh, Da Nang, Lao Cai, Nha Trang, Da Lat, Mong Cai, HoiAn, Dao Phu Qioc and Mui Ne have strong degree centrality and strong aggregation and radiation ability to other tourism nodes. The closeness centrality of Ha Noi, Ho Chi Minh, Da Nang, Lao Cai, Nha Trang, Da Lat, Mong Cai, Hoi An, Dao Phu Quoc, Vinh Ha Long and Sa Dec is high. This means that the mobility between these nodes and other nodes is very good. The betweenness centrality of Ha Noi, Ho Chi Minh, Da Lat, Da Nang and Lao Cai is high. These five travel nodes have strong control over other travel nodes. The confirmation of important tourism nodes provides scientific basis for Vietnam to rationally plan regional tourism resources, develop and design tourism routes, plan and construct tourism infrastructure and improve tourism 
transportation system.

This study once again verifies the research value of online travel notes. Compared with the questionnaire survey, the information of digital footprint in online travel notes is more objective. There are still some shortcomings in this study need to be improved. Due to lack of demographic data of tourists in the online travel notes information, such as age, occupation, income, and education level and so on, the demographic analysis of samples cannot be conducted. There is no structural holes analysis on the of network structure of Chinese independent tourists to Vietnam.

The future research direction can be carried out from the following aspects: first, Vietnam can be divided into three parts: north, central and south, and the tourism flow of each area should be analyzed. Secondly, the research content of tourism flow should be expanded to include the analysis of network structure hole. From the perspective of spatial and temporal distribution of tourism flow, the characteristics of Chinese independent tourism flow to Vietnam should be studied. Finally, the source of tourism flow of Chinese independent tourists to Vietnam is studied, that is, the main source cities of Chinese tourists are studied, providing a basis for Vietnam to develop China's tourism market and carry out precise marketing.

\section{Acknowledgment}

This study was supported by the Sehan University Research fund in 2020.

\section{References}

Borgatti, S. P., \& Everett, M. G. (2000). Models of core /periphery structures. Social Networks, (4), $375-395$. https://doi.org/10.1016/S0378-8733(99)00019-2

Bowden, J. (2003). A cross-national analysis of international tourist flows in China. Tourism Geographies, 5(3), 257-279. https://doi.org/10.1080/14616680309711.

Freeman, L. C. (1978). Centrality in social network conceptual clarification. Social Networks, 1(3), $215-239$.

Freeman, L. C. (2004). The development of social network analysis: A study in the sociology of science. Vacouver, CA: Empirical Press.

Jansen-Verbeke, M., \& Spee, R. (1995). A regional analysis of tourist flows within Europe. Tourism Management, 16(1), 73-80. https://doi.org/10.1016/0261-5177(95)93433-W

Leiper, N. (1990). Tourist attraction systems. Annals of Tourism Research, 17(3), 367-384. https://doi.org/10.1016/0160-7383(90)90004-B

Lim, C. (2004). The major determinants of Korean outbound travel to Australia. Mathematics and Computers in Simulation, 64(3-4), 477-485. https://doi.org/10.1016/S0378-4754(03)00113-7

The Statistics of Chinese tourists to Vietnam. (2019). General Statistics Office of Vietnam [Internet]. Vietnam: The Statistics of Chinese tourists to Vietnam [updated 2019 Dec 10; cited 2018 Dec 31]. Retrieved from https://www.gso.gov.vn/default_en.aspx?tabid=780

Wang, C. Y., Jang, P. S., \& Kim, H. H. (2019). A study on the characteristics of the seasonal travel path of individual Chinese Travellers in Korea. Korea Convergence Society, 10(7), 23-31.

Wang, C. Y., Jang, P. S., \& Kim, H. H. (2019). A study on the characteristics of travel flow of independent tourists from China to South Korea based on tourists' digital footprint. The Society of Digital Policy \& Management, 18(1), 111-119.

Wang, J. Y., Wu, J. F., Tang, L., \& Yang, X. J. (2013). Research on the properties and structural characteristics of inbound European tourist flows network in China based on SNA. Human Geography, (06), 147-153. https://doi.org/10.13959/j.issn.1003-2398.2013.06.019

Williams, A. V., \& Zelinsky, W. (1970). On some patterns in international tourist flows. Economic Geography, 46(4), 549-567. https://doi.org/10.2307/142940

Wu, J. F. (2014). Distribution of inbound foreigner tourist flows and its property and structure characters in China. Journal of Arid Land Resource and Environment, 28(07), 177-182. https://doi.org/10.13448/j.cnki.jalre.2014.07.036

Wu, Z. T., Liu, J. H., \& Yuan, J. (2016). Network analysis and evolutionary studies based on tourist flow of mainland residents' self-service traveling in Taiwan. Tourism Tribune, 31(10), 113-121.

Yan, X., Zhai, L., \& Fan, W. (2013). C-index: A weighted network node centrality measure for collaboration competence. Journal of Informetrics, 7(1), 223-239. https://doi.org/10.1016/j.joi.2012.11.004 